\title{
Dual Specificity Protein Phosphatase 6
}

National Cancer Institute

\section{Source}

National Cancer Institute. Dual Specificity Protein Phosphatase 6. NCI Thesaurus. Code C106026.

Dual specificity protein phosphatase 6 (381 aa, $\sim 42 \mathrm{kDa}$ ) is encoded by the human DUSP6 gene. This protein plays a role in both dephosphorylation and inactivation of mitogen-activated protein kinases. 